\title{
Assessment of the Effectiveness of Chilling Method in Mitigating Human-Elephant Conflicts in Western Serengeti, Tanzania
}

\author{
Mdee Norah .V ${ }^{1}$, Zella Adili .Y ${ }^{2}$ \\ ${ }^{1}$ Tanzania Wildlife Research Institute, Mahale/Gombe Research Centre, P.O. Box 1053, Kigoma, Tanzania \\ Tel. +255-28-2802072/ +255-784-687137/+255-758-506207
}

\begin{abstract}
${ }^{2}$ Department of Economic Studies, The Mwalimu Nyerere Memorial Academy (MNMA)-Zanzibar, P.O Box 307 Zanzibar, Tanzania

Tel: +255 $242250315 ;+255787260448$
\end{abstract}

\begin{abstract}
This paper reveals the less known effectiveness of Chilling method in mitigating human elephant conflicts carried out in Western Serengeti, Tanzania. Two villages were involved namely Nyamburi and Bonchugu. Data were collected by using household questionnaire, focus group discussion and archive information. Data were analyzed by use of SPSS (Version 18) software.Field results indicates that; Chilling method is effective (83\%)in mitigating human elephant conflicts. However, statistics for crop damaged by elephants before and after introduction of the method shows that the crops damage decreased by 25\%. The most observable strengths of the method were; it control HEC without harm people and elephants, it is easy to apply (55\%), it does not consume time and use appropriate technology. Despite the effectiveness of the method, major weaknesses observed to face the method were; insufficient used oil and pepper (61\%), elephants observed to be a clever animal as sometimes they inter into the farms backwards and also during rain seasons, chill method observed to be ineffective as it can be washed/removed easily. However, the respondents recommended that; the challenges can be solved by local community to cultivate pepper and other stakeholders such as district, different $N G O$ and companies to support farmers the provision of used oil, chill should be applied regularly once washed out by rain and for the effectiveness of the method community should be more trained on how to use the method.
\end{abstract}

Keywords - Human-elephant conflict (HEC), Chilling method, Crop raids.

\section{INTRODUCTION}

\subsection{Background information}

Protected areas (PAs) are important in the conservation of biodiversity, economic value of resources and their potential to contribute to sustainable development (URT, 2005). Despite this development, local people living adjacent to the PAs live in abject poverty and human wildlife conflict (Kaswamilaet al, 2007). Human elephant conflict (HEC) is a growing global problem which is common to all areas where elephants and human population coexist as well as share resources (Distefano, 2005). HEC occurs wherever people and elephants coincide, and poses a serious challenge to wildlife managers, local communities and elephants alike.

Human elephant conflicts are one of the major threats to conservation in Africa (Holmern\& Anne, 2004). HEC occurs throughout the elephant range, and has been reported in most of the 37 elephant range states of the African continent in both savanna and forest situations (Parker et al., 2007). Hence, knowledge about human-elephant conflict in and around protected areas is crucial in wildlife management (Holmern\& Anne, 2004; Kideghesho, 2006).

In several parts of East Africa Conflict between elephant and local communities are wide spread and are major concern for both elephant conservation and rural development (Distefano, 2005).HEC in East Africa is increasingly becoming significant as human populations and agricultureexpand into elephant habitat (ibid). Elephants continue to threaten farmers' income and food security despite considerable research and resources that has been devoted to resolving this problem (Woodroffe et al., 2005). In Tanzania encroachment of protected areas by local communities has resulted into tremendous human wildlife conflict (Severre, 2000).

To mitigate HEC, farmers use both lethal and non-lethal measures such as fencing, scares, chilling, barriers, translocation and use of guard animals (Breitenmoseret al., 2005). In order to be conservation-effective, non lethal methods must be acceptable (in accordance with local traditions) and applicable on a large scale(cheap and easy to use) (Woodroffe et al., 2005). Furthermore, the implementation and application of non-lethal techniques must be considered in the context of the conservation goals and all other management action (ibid) 1.2

\subsection{Statement of the Problem}

Conflict between humans and African elephants occur wherever they coexist, especially in the interface between the elephants' range and agricultural land. Most HEC incidents involve crop-raiding animals that consume or destroy food crops and injure or kill those people trying to protect their fields (Distefano, 2005). 
The Serengeti ecosystem in Tanzania embodies a variety of human elephant conflicts as evidenced both within and around the protected areas of the ecosystem (Homewood et al., 2001).). The root cause of human-elephant conflict is the exploding human population growth and resultant pressure on elephant habitat (Parker et al, 2007).According to Kaswamila (2009), HEC is more alarming in Serengeti district. Crop destruction by elephant impacted on both household food security and cash income. The annual crop loss is estimated to amounts to 390 tones from annual crop yields of 129,670 tones of various crops .

In trying to address the problem, the Tanzania Wildlife Research Institute in collaboration with Serengeti District Council intervened by introducing the use of chilli (pepper) in mitigating destruction of crops by elephants. However since its introduction in 2007, no study has been carried out to assess its effectiveness. This study is an attempt to that end.

\subsection{Research Objectives \\ 1.3.1 General Objective}

The main objective of this study was to assess the effectiveness of chilling method in mitigating HEC in Western Serengeti.

\subsubsection{Specific Objectives}

Specifically this study intended to:

(i) Assess effectiveness of chilling method

(ii) Identify strengths and weakness of the method

(iii) Suggest measures for improvement

\subsection{Conceptual Framework}

For effective control of Human Elephant Conflict, good application of chilling method will be very much needed. In order for the method to be applicable, there must be a positive community attitude towards control of elephants and community should be well trained on chill application. Furthermore, the control will be effective if the elephants will not be habituated and there is conducive environment for chill application such as absence of rain as chill is affected by rain.

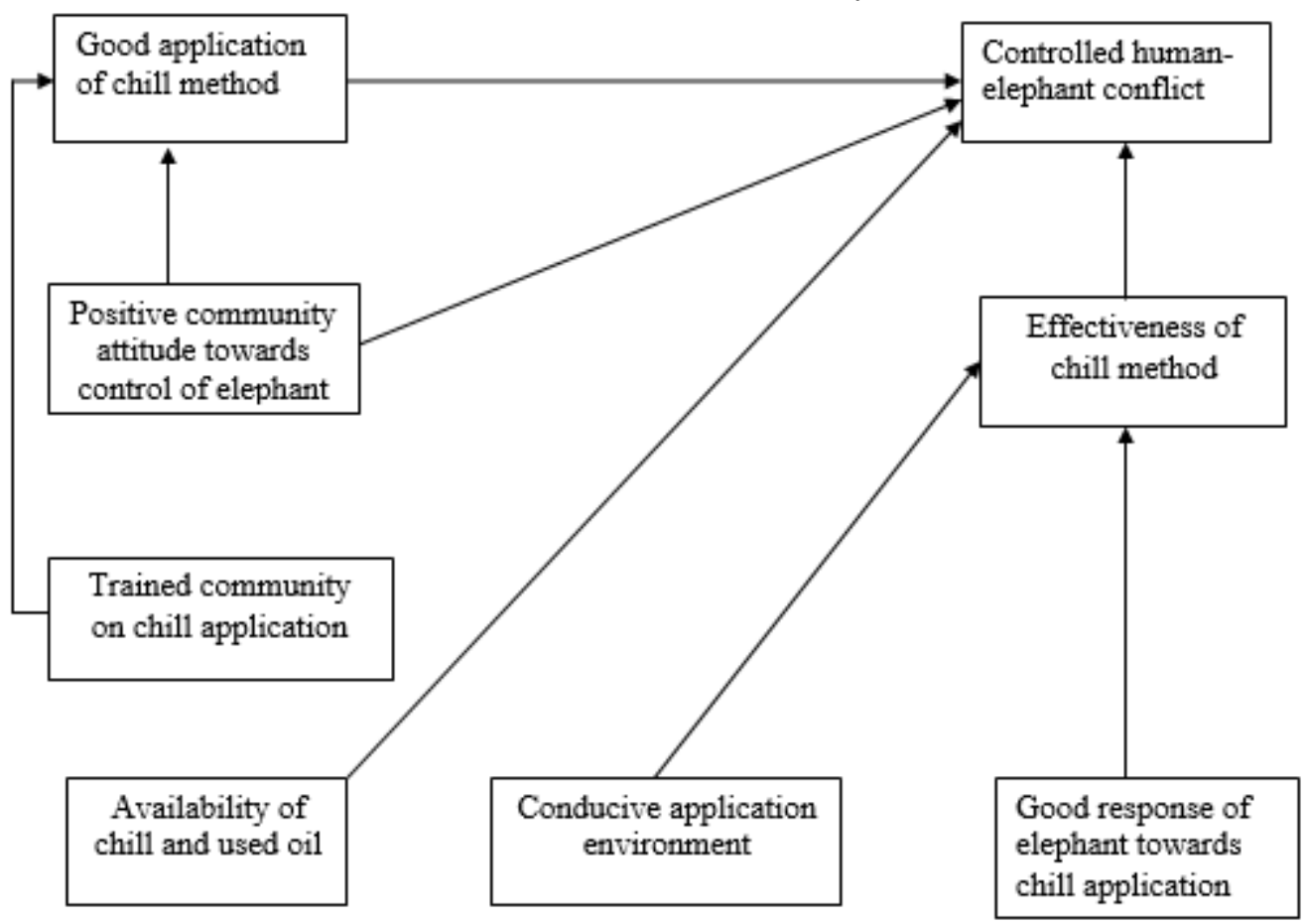

Fig.1: Conceptual Frame work

\subsection{The Study area}

\subsubsection{Location}

Nyamburi and Bonchugu are among villages in Serengeti District. (See figure 1). Nyamburi villagelies between $34^{\circ}$ $40^{\prime \prime} \mathrm{E}$ and $1^{\circ} 47^{\prime \prime} \mathrm{S}$ while Bonchugu village lies between $34^{\circ} 45^{\prime \prime} \mathrm{E}$ and $1^{\circ} 50^{\prime \prime} \mathrm{S}$ with an average altitude of $1480 \mathrm{~m}$ (SDC, 2011). Nyamburi has a total population of 3865 people and 787 households while Bonchugu has total population of 6114 and 579 households. 


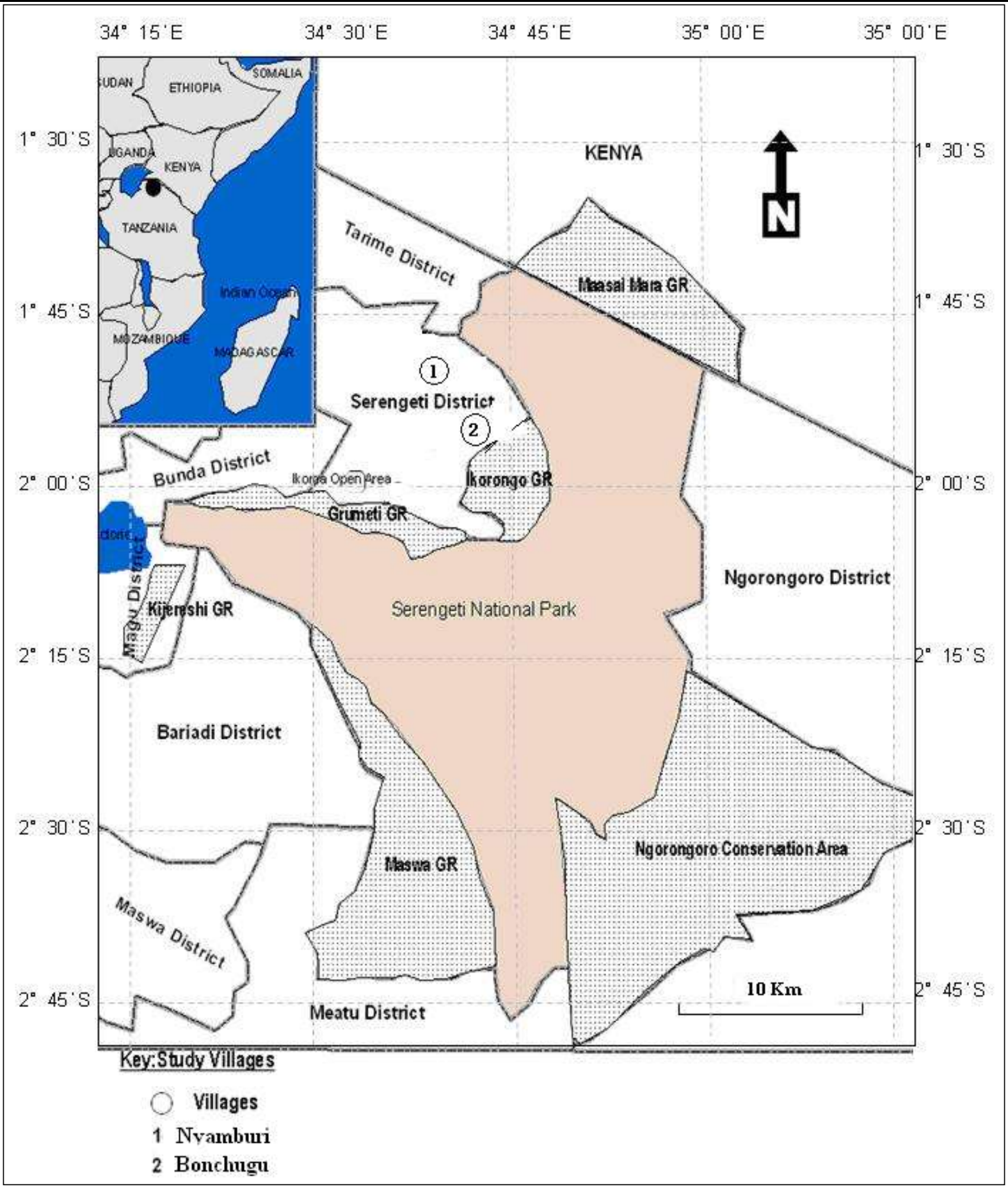

\subsubsection{Climate and topography}

The study villages are part of the high interior plateau of East Africa. It slopes to its highest part $(1850 \mathrm{~m})$ on the eastern plains near the Gol Mountains towards Speke Gulf $(920 \mathrm{~m})$ along Lake Victoria. The temperature shows a relatively constant mean monthly maximum of $27^{0}-28^{\circ} \mathrm{C}$. The minimum temperature varies from $16^{0} \mathrm{C}$ in the hot month of October-March to $13^{\circ} \mathrm{C}$ during May-August (SDC, 2011). Rain typically falls in a bimodal pattern with the long rains during March-May and the short rains during
November-December. Rainfall varies from $1200 \mathrm{~mm}$ in the north to $600 \mathrm{~mm}$ on the south-eastern plains and the Rift Valley (ibid).

1.5.3 Economic activities

About three quarters of the population in the study villages are mainly small-scale farmers who, to a varying degree complement with livestock keeping (Holmern, et al., 2004). Livestock (cattle, sheep and goats) which is kept by $61 \%$ of the population is seen both as a source of income and a 
source of meat for consumption and some $73 \%$ earn income from the sale of animals or meat (ibid). Wildlife-induced damage to crops and domestic animals is a major problem in the area (SDC, 2011).

\subsection{The Study Area Selection}

\section{RESEARCH METHODOLOGY}

The study was conducted in Bonchugu and Nyamburi villages adjacent to Western Serengeti. These villages were selected because the problem of HEC is more alarming due to human elephant interaction and proximity to Serengeti National Park.

\subsection{Sample size and Sampling technique}

A totalof 82 respondents were picked. Sample size composition included (68) households respondents, (2) Village chairperson, (2) VEO,(1) DGO, (1) DALDO, (2)SENAPA Ecologist, (2) Elders,(2) Youth and (2) women.In determining the sample size two factors were considered: required level of precision in the results and the available budget.

According to Hennet al., 2006, it is worth mentioning that, it is the absolute size of the sample, which is important in determining the sample size, not its size relative to the population. Sixty eighty households from each Village were sampled from the Village register list using a simple random sampling method. Where a candidate happened to come from the same household, one was dropped. The age from 18 and above was picked from each household using a table of numbers following the procedures described in Bouma (2000). Simple randomly sampling is considered to be simpler and more cost effective system (Henn et al., 2006). Key informants and group discussion members were selected purposively to meet the objectives of the study.

\subsection{Data collection methods \\ 2.3.1 Questionnaire survey}

Face-to-face semi-structured questionnaires were administered to the sampled households. Semi-structured questionnaire survey was preferred to structured because it normally yields better quality data than the latter. According to Gillham (2005), Semi-structured questionnaire allows the interviewer greater flexibility at the expense of possibly incurring greater bias as the same questions may be asked in the same order but supplementary questions (probes) may be allowed to clarify the responses. The household questionnaire contained aspects such as: socio-economic characteristics, crop destruction, and assessment of chilling method, strengths and weaknesses of the method and suggestions for improvement.

\subsubsection{Questionnairepre-testing}

Questionnaire pre-testing aimed to test questionnaire wording, sequencing and layout; to train fieldworkers; and to estimate response rates and time. Pre-testing also assessed whether the questions are clear, specific, answerable, interconnected and substantially relevant. The exercise helped to fine-tune the questionnaire. Some ambiguous questions were removed and others were rephrased. After revision, the questionnaires were duplicated ready for use in the social survey.

\subsubsection{Questionnaire administration}

Face to face household semi-structured questionnaire surveys were administered by the researcher and research assistants to interview sample local residents in Villages.Research team visited the selected household sample at their residential areas. The questionnaire consisted both open and closed end questions. The openended questions were intended to give respondents an opportunity to express their views more freely and to increase the level of interaction between the two subjects.

\subsubsection{Focus group discussion}

Focus group discussion (FGD), help researcher tap many different forms of communication that people use in day to day interactions, including jokes, anecdotes, teasing and arguments (Morgan,1998). FGD needs to comprise 5 to 10 people so as to have effective and participatory group discussion (Krueger et al.,2004). In this study FGD comprised 6 people. A checklist was used to obtain information's from villages elders, women and youths (group members). During discussion the researcher acted as a facilitator to make sure that every one participates effectively.

\subsubsection{Archive information}

Documented information in Village, ward and District offices related to average crops destroyed by elephants, Introduction of chilling method to the district, location and population of the study villages. Similar information was also obtained from Village experts (agriculture and wildlife officials). This information supplemented data collected from interviewed households.

\subsubsection{Direct field Observation}

Field observation was made for the purpose of observing farms located adjacent to protectedareas to compare the incidence of destruction as compared to distant villages. Also field observation was made to observe the way chilling method was applied by the farmer. Using physical visit as a tool for data collection, the observer goes to the field and makes the study of the phenomena and once observes things in a scientific manner, he or she thoughtfully studies the fact (Rwegoshora,2006).

\subsection{Data analyses}

Data collection using questionnaire survey, group discussion and archive information were mainly qualitative in nature. As pointed out by several social science researchers, qualitative data analysis has no one right way to proceed with analysis (Hesse-Biber\&Leavy, 2004) and this necessitated use of coding and memoing for narrative information and/or secondary data. Coding is the reading 
the text line by line and carefully coding each line, sentence and paragraphs thereby describing themes/ideas (Punch, 2000). Memoing (memo writing) on the other hand is the theorising write up of the ideas about codes, which assist researchers to illuminate ideas and relationships in the data (ibid.).

Before the detailed data analysis, questionnaires were thoroughly examined, variables coded and then imported into SPSS version 18 software package. This examination process will be done to all questionnaires used in the survey. The data analysis then followed the two main stages of reduction and display (Coffey \& Atkinson, 1996). Data reduction involved editing and summarizing of data through coding. With data already entered into SPPS and secondary data from government offices and group discussion, data analysis to answer research questions were carried.

\section{RESULTS AND DISCUSSION}

3.1 Social economic characteristics of respondents The socio-economic characteristics of the study area are presented in Table 1 below. Overall, in the two villages combined, the majority of the respondents were males $(60 \% ; \mathrm{N}=68)$. As for age most of the respondents $(68 \%)$ were between 18 and 54 years. This shows that the majority of the populations at study villages are still economically productive. Regarding social economic activities of the study villages, about $78 \%$ of the population depends on crop-based agriculture.

Table.1: Social economic characteristics of respondents

\begin{tabular}{|c|c|c|c|c|c|c|c|c|c|c|c|c|c|c|}
\hline \multirow[t]{2}{*}{ Village } & \multirow[t]{2}{*}{$\begin{array}{l}\mathbf{N} \\
=68\end{array}$} & \multicolumn{2}{|c|}{$\operatorname{Sex}(\%)$} & \multicolumn{3}{|c|}{ Age (\%) } & \multicolumn{3}{|c|}{ Education (\%) } & \multicolumn{2}{|c|}{$\begin{array}{l}\text { Socio- } \\
\text { economic } \\
\text { activities } \\
(\%)\end{array}$} & \multicolumn{3}{|c|}{ Household size\% } \\
\hline & & $\mathrm{M}$ & $\mathrm{F}$ & $\begin{array}{l}18- \\
34\end{array}$ & $\begin{array}{l}35- \\
54\end{array}$ & $>54$ & $\mathrm{NF}$ & $\mathrm{P}$ & $\begin{array}{l}\mathrm{S} \\
\& A\end{array}$ & $\mathrm{~A}$ & $\mathrm{~L}$ & $1-5 p$ & 6-10p & $>10 p$ \\
\hline Nyamburi & 34 & 61 & 39 & 30 & 36 & 34 & 41 & 55 & 4 & 76 & 24 & 10 & 53 & 25 \\
\hline Bonchugu & 34 & 58 & 42 & 32 & 38 & 30 & 38 & 57 & 5 & 80 & 20 & 12 & 50 & 50 \\
\hline Average & 34 & 50 & 40.5 & 31 & 37 & 32 & 40 & 56 & 4.5 & 78 & 22 & 11 & 51.5 & 37.5 \\
\hline
\end{tabular}

Keys: $\mathrm{N}=$ sample size $\mathrm{M}=$ Male $\mathrm{F}=$ female $>=$ Above $\mathrm{NF}=$ Non Formal $\mathrm{P}=$ Primary $\mathrm{S} \& \mathrm{~A}=$ Secondary and AboveA= AgricultureL=Livestock $\mathrm{p}=$ person

The literacy level in these two villages is low as only $(4.5 \%)$ have attained secondary education. This implies that, the illiteracy level in terms of formal education is high. Education is a necessary condition for social economic and technological development in any society(Author, pers. Obs.).With education one can easily learn new technological advancement, adapt to change environmental conditions and learn new skills.

Regarding household size, findings reveals that, the average size of household is 8 people. The higher number of family size could probably be due to polygamy culture of the people in the area. InMara region,particularly Serengeti and Tarime districts the culture of marrying many wives is rampant (Author, pers. Obs.).Having many wives increases the probability of having many children when compared to monogamy families and hence increased poverty level. This is in agreement by Kaswamila (2007) where he observed that income in the study area ranged between TZS784,000 and 930,000 .

\subsection{Human Wildlife Conflict (HWC) status}

Local communities were asked to assess the current status of HWCs in their areas. Answers were limited to Yes or No.
In both villages the findings reveals that, $\mathrm{HWC}$ is a problem (Figure 3). In Nyamburi all respondents perceived HWC a problem whereas in Bonchugu the proportion was 97\%. The most destructive game being elephants (Lexodanta Africana), other problem animals includedwild pigs (Potamochoerusporcus),

porcupine (Potamochoerusporcus), vervet monkeys (Cercopithecus aethiops), wildebeest (Connochaetestaurinus), warthog (Phacochoerusaethiopicus) and gazelle (Gazella grant). The most affected crops were maize, sorghum and finger millet which are basically the main staple food in the study area. The reasons for favouring these crops could not be established. However, probably thereasons couldbe the nature of the crops and elephants prefer succulent crops.Results from Focus Group Discussion (FGDs) revealed that,crop damage by elephants not only affect farmer's ability to feed his or her family, but also reduces cash income and has repercussions for health, nutrition, education and ultimately, development. As farmers depends on crops for selling to obtain cash for school fees 


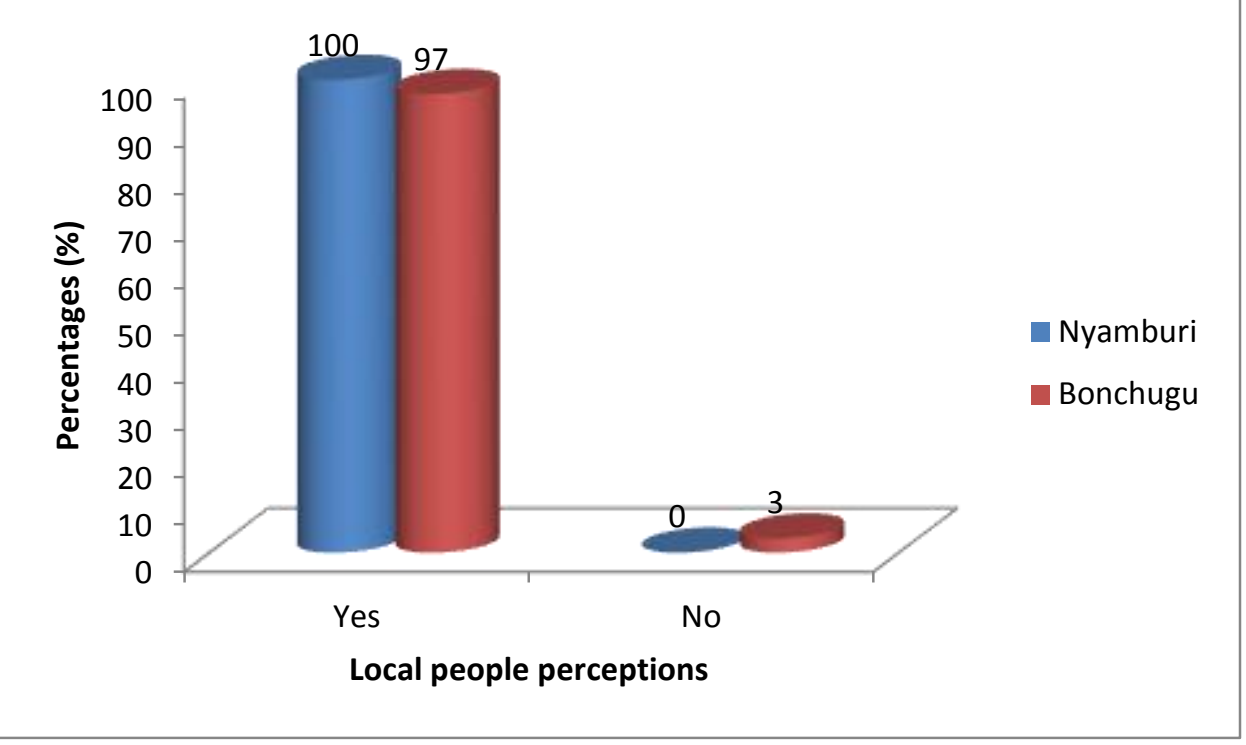

Fig.1: Local community perception on HWC status

\subsection{Assessment of effectiveness of chilling}

The effectiveness of the method was assessed through local people perception and through the status of crop destruction by elephants before the introduction of chill and after the use of the method.

Table.2: Households perception on effectiveness of chilling method

\begin{tabular}{|l|c|c|c|}
\hline Village & \multirow{2}{*}{$\begin{array}{l}\text { Sample } \\
\text { size } \\
\end{array}$} & \multicolumn{2}{|c|}{ Perceptions \% } \\
\cline { 3 - 4 } & & $\begin{array}{l}\text { Chilling is } \\
\text { effective }\end{array}$ & $\begin{array}{l}\text { Chilling is not } \\
\text { effective }\end{array}$ \\
\hline $\begin{array}{l}\text { Nyamb } \\
\text { uri }\end{array}$ & 34 & 77 & 23 \\
\hline $\begin{array}{l}\text { Bonchu } \\
\text { gu }\end{array}$ & 34 & 90 & 10 \\
\hline Average & 34 & 83.5 & 16.5 \\
\hline
\end{tabular}

They argued that, the incidence of destruction by elephants has gone down. For example one respondent had this to say: "We thank the government and Tanzania Wildlife Research Institute (TAWIRI) for introducing this method of deterring elephants, we were not happy with the situation." Jones \& Elliott (2006), in their study in Namibia found that; chilling method is effective because it worked as olfactory deterrent for elephant.

Focus group discussant's view on the effectiveness of the method was that,the method is effective because it has improved food security through reducing crop raids. Interview with District Game Officer (DGO) on the matter revealed that chilling has been instrumental in mitigating HEC.When asked to give reasons for,he argued that; elephants have a highly sensitive olfactory system and chilies therefore cause them pain. Thisargument is

\subsubsection{Local Communities perception}

Local communities were asked to assess if the method is effective or not. Results indicate that more than $80 \%$ were of the opinion that chilling method was effective in mitigating HEC (Table 2).

supported by Hoare (2001), who argues that chillsare effective in deterring elephants due to its irritant properties.

3.4 Status of destruction by elephants before and after introducing chilling method

The status of destruction of crops (crop raids) by elephants before and after the introduction of chill was assessed. Data were obtained from District Game Officer (DGO).

3.4.1 Status before introduction of chilling method in Nyamburi village

In Nyamburi village, crop destruction over years (20032006) fluctuated (Figire 4). The average destruction was about $367 \mathrm{ha} / \mathrm{annum}$. This seems to be extremely high. Taking into the account, the total arable land of the area which is $2450 \mathrm{ha}$; thedestruction is about $15 \%$ of the total arable land.Assuming the destruction was for maize which is the most preferred crop by elephants and which is also a staple food in the area. This situation has two implications; that is, in food security and cash income. In the study area the crop is of multipurpose nature. That means is used as cash crop as well as food crop. For example assessing maize yield/ha in the area which is 5bags/ha;this implies that the loss of $367 \mathrm{ha} /$ annum is equivalent to 182 tones of maize/annum which could feed a large number of families.According to Kaswamila (2007) one family consume 0.72 tone/year therefore the loss of 182 tones means food shortagefor 2000people. 


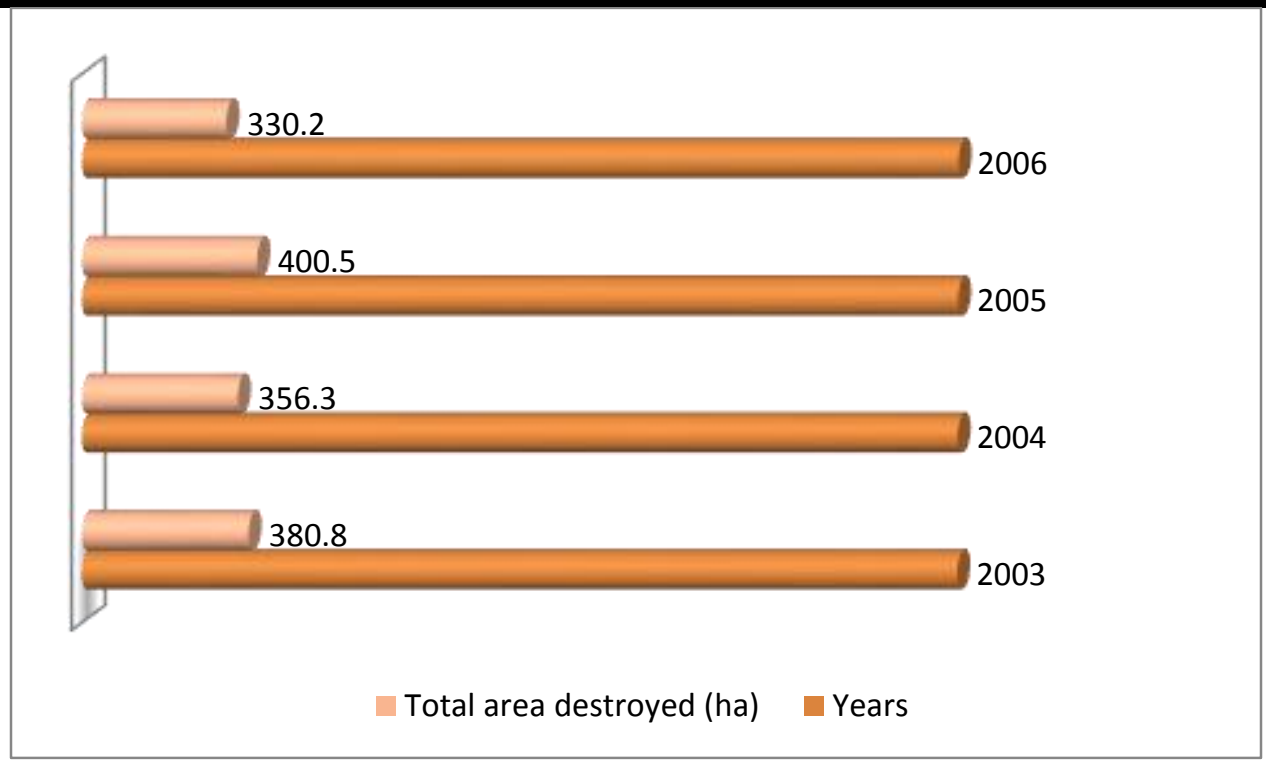

Fig.2: Extent of elephant destruction at Nyamburi village before introduction of Chilling method (2003 - 2006)

\subsubsection{Status after introduction of chilling method in Nyamburi village}

The situation of elephant's crop destruction status at Nyamburivillage after the introduction of chill was also assessed (Figure 5).Results indicate that the trend of crop destruction in general decreased. This could be argued that,among other things, probably the method has been instrumental in deterring elephants. On average only $231 \mathrm{ha}$ was destroyed between 2007and 2010 which was $25 \%$ lower compared to the situation before chill introduction. Therefore the method is effective in mitigating HEC.

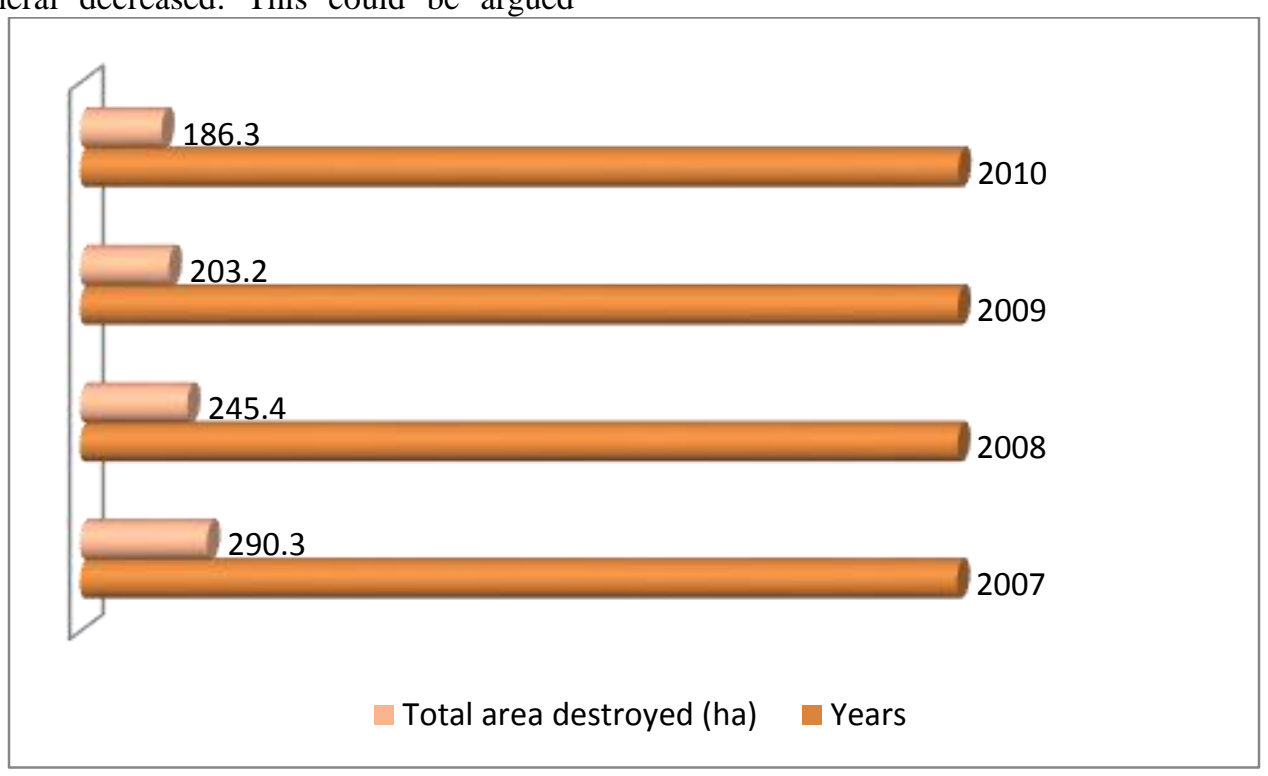

Fig.3: Extent of elephant destruction at Nyamburi village after introduction of Chilling method (2007 - 2010)

3.4.3 Status before introduction of chilling method in Bonchugu village

In Bonchugu results show that, crop destruction over years (2003-2006) also fluctuated (Figure 6). However, by all standards the average destruction of $401 \mathrm{ha} / \mathrm{annum}$. This was relatively higher compared to Nyamburi. Taking into the account, the total arable land of the area which is 1273.8 $\mathrm{Ha}$; destruction was about $32 \%$ of the total arable land. 


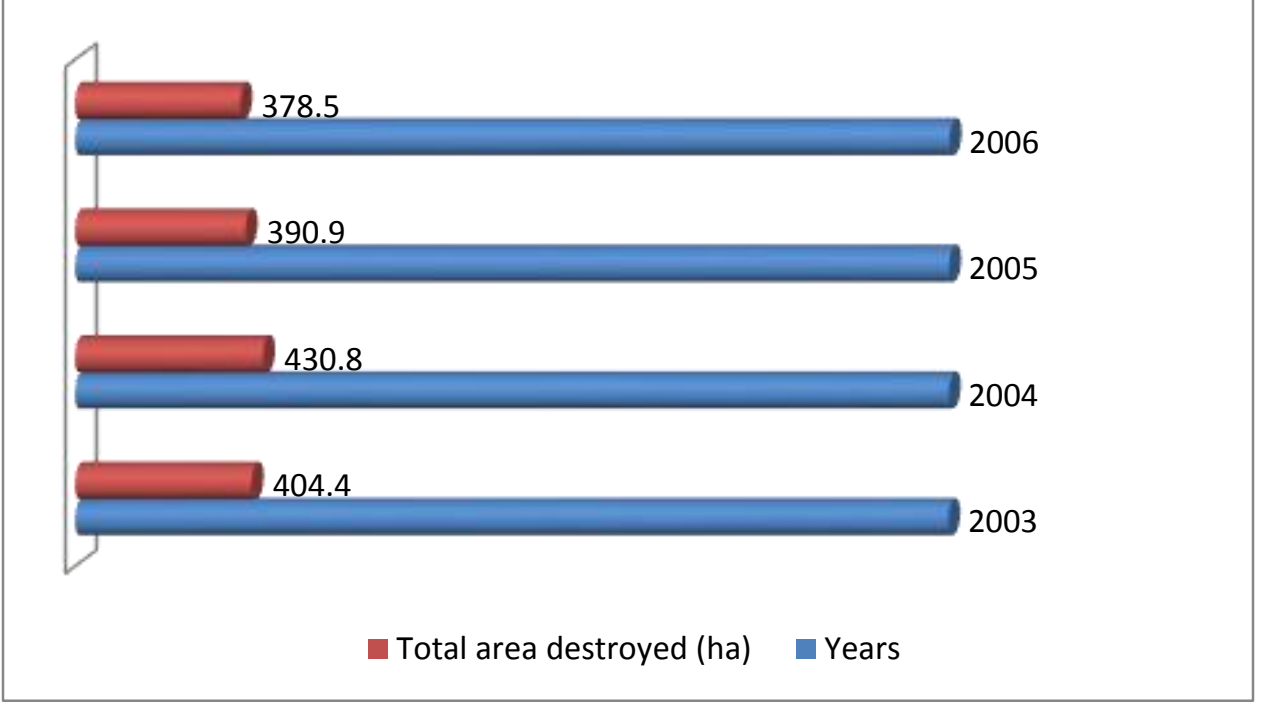

Fig.4: Extent of elephant destruction at Bonchugu village before introduction of Chilling method (2003 - 2006)

\subsubsection{Status after introduction of chilling method in Bonchugu village}

The situation of elephant's crop destruction status atBonchuguvillage after the introduction of chill was also assessed (Figure 7).Results indicates that the trend of crop destruction was decreasing at a decreasing rate. The decline trend could probably due to the effective of the method. On average only 291 ha was destroyed between 2007and 2010 which was $25 \%$ lower compared to the situation before chill introduction. This could be argued that, among other things, the method is instrumental in deterring elephants.

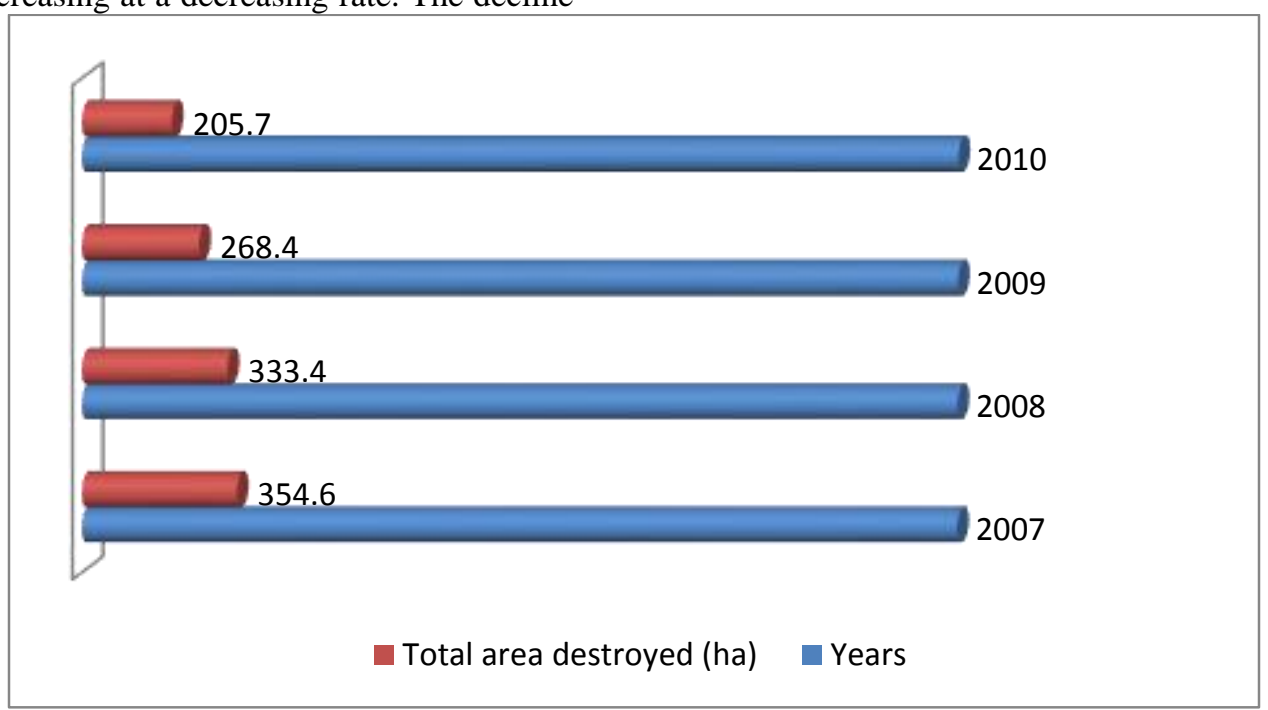

Fig.5: Extent of elephant destruction at Bonchugu village after introduction of Chilling method (2007 - 2010)

A study made by Jackson et al. (2008) shows that, chill method definitely works as crop raids from elephants every year in Zambia witnessed to decrease after farmers received training from Zambian trainers on how to use chili pepper to stop elephants raiding farmers field. According to Parker and Osborn (2006), it is estimated that in 2001, farms close to the eastern wing of Kakum National park (Ghana) where elephant activities were highest, recorded between 0.5 bags of maize/ha during the main season depending on the number of wildlife damage the farm had. In 2003, such farms recorded up to 7 bags/ha after chilling crop raiding deterrents were put in place to scare off elephant.

\subsection{Strengths of chilling method}

Perception of local communities on the strengths of chilling was sought through questionnaire survey and group discussions (Table 3). Questionnaire results show several strengths. In order of importance the strengths viewed by households in both villages were easiness to use in field.Other strengths were cost effective of the method and itis user friendly.During FGDs the most observed strengths were for the chill to be harmless to both human and elephants and that it is simple to use.. InZambia Jackson et al. (2008), found that, when the crops supply with chillies, as an olfactory deterrent for elephants, it was sufficient, without harm both human and elephant. 
Table.3: Strengths of chilling method

\begin{tabular}{|l|l|l|l|l|}
\hline Villages & \multirow{2}{*}{$\mathrm{N}=68$} & Views & \multicolumn{3}{|c|}{} \\
\cline { 3 - 4 } & & Households & $\%$ & FGD \\
\hline Nyamburi & 34 & Easiness in use & 58.6 & Control HEC without harming people \\
\cline { 3 - 4 } & & Cost effective & 22.3 & and elephant \\
\cline { 3 - 4 } & & User friendly & 19.1 & \\
\hline Bonchugu & 34 & Easiness in use & 51.2 & Its use is simple and use appropriate \\
\cline { 3 - 4 } & & User friendly & 31.4 & technology \\
\cline { 3 - 4 } & & $\begin{array}{l}\text { It use simple } \\
\text { technology }\end{array}$ & 17.4 & \\
\hline
\end{tabular}

\subsection{Weaknesses of Chilling method}

Research findings from households revealed several weaknesses (Figure 8). The most notable one was the tendency of elephant to inter in the farm backwards after recognition that, chill deter them by generating unpleasant smell. Other weakness observed by households was the effect of heavy rainfall. They revealed that, insufficient used oil and chill. During FGDs they revealed that during rain seasons the pepper can be removed easily hence the method becomesineffective. Results from FGD do not differ with that of households. Theyargued that, elephantsare clever animals, they soon learn that, they pose no real threat

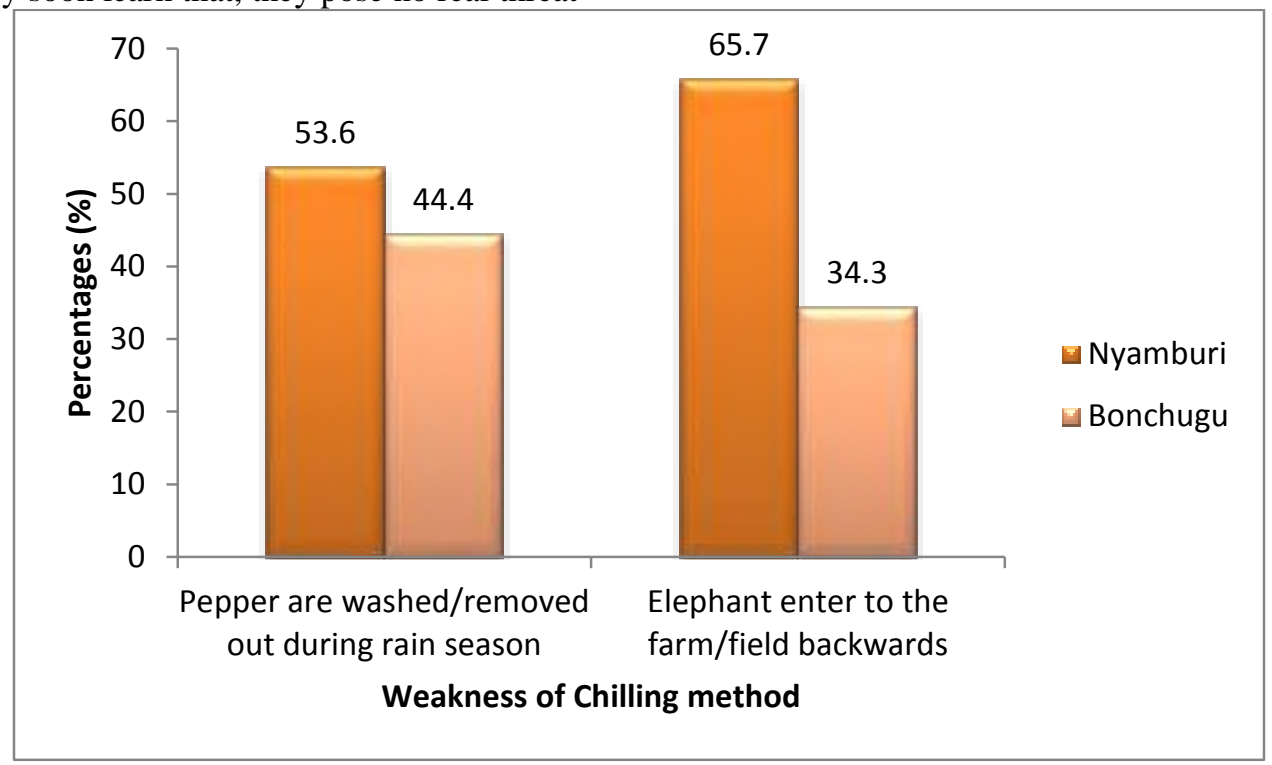

Fig.6: Weaknesses of Chilling method

\subsection{Suggested measures for Improving Chilling Method.}

Suggestions for local communities on the improvement of the method weresought through Questionnaire survey, group discussions and government officials (Table 4). and then ignore them, with time they entering in the farms/field backwards.Muruthi, (2005), argument on weaknesses of chilling method were similar with FGDs.He pointed out that, chilling method like other modern method face the same problem of elephants to overcome their fear by becoming habituated and less effective overtime.DGO argued that, the availability of pepper and used oil does not match with the high demands. In northern Mozambique for instance, in a region where chili-pepper has been tried, villagers very rapidly lost confidence in the method, due to difficult in maintaining the deterrent (FAO, 2005). 
Table.4: Suggestions for improving chilling method

\begin{tabular}{|c|c|c|c|}
\hline \multirow{2}{*}{ Villages } & Households & FGDs & Officials \\
\hline \multirow{2}{*}{ Nyamburi } & $\begin{array}{c}\text { Chill pepper cultivation by } \\
\text { community and } \\
\text { provision of used oil }\end{array}$ & $\begin{array}{c}\text { Provision of used oil from } \\
\text { different organizations and } \\
\text { more training of community } \\
\text { on chill application }\end{array}$ & $\begin{array}{c}\text { Chilli pepper cultivation } \\
\text { by community and } \\
\text { provisions of used oil } \\
\text { from surrounding } \\
\text { companies and institutions }\end{array}$ \\
\hline Bonchugu & $\begin{array}{c}\text { Chill pepper cultivation and } \\
\text { provision of used oil }\end{array}$ & $\begin{array}{c}\text { Regular application of chill } \\
\text { once washed out by rain } \\
\text { and Provision of used oil } \\
\text { from different organization }\end{array}$ & $\begin{array}{c}\text { Positive community } \\
\text { attitude towards the } \\
\text { control of the elephant }\end{array}$ \\
\hline
\end{tabular}

The most suggested measures byhousehold's respondents and FGDs were about the farmer to cultivate chill pepper and availability of used oil from surrounded companies and different institution. However the study made by Kiokoetal.,(2006), show that cultivation of chill will depend on farmer investment, climate and soil suitability, as well as the ability to market such crops. The benefits of having elephants living close to communities must exceed the cost of daily or constant exposure to people and their arable land (ibid).

It was also suggested that, chill should be applied regularlyonce washed out by rain and for the effectiveness of the method community should be well trained on how to use the method.

DGO suggested that,farmers should cultivate peppers, and he has already involved Districts authorities andBarick Company Limited as the supplier of used oil to the farmer to improve the method. He also suggested that for the method to be more effective, community should have positive attitude towards the use of the method. FAO, (2005), suggestions on improvement of chilling method does not differ with that of households' perceptions and DGO. They suggested that, government or NGO support is required to maintain the deterrents over most of the more remote areas where human-elephant conflict occurs.

\section{CONCLUSION AND RECOMMENDATIONS 4.1 Conclusion}

The results of the study revealed that; chilling method is effective in mitigating HEC.The most observable strengths of the method was that; it can deter elephants without harming people and elephants, it is easy to apply, it does not consume time and use appropriate technology.Despite the effectiveness of the method, major challenges which observed to face the method were; insufficient used oil and pepper, elephants observed to be a clever animal as sometimes they inter into the farms/field backwards and alsoduring rain seasons, chill method observed to be ineffective as it can be washed/removed easily.However, the respondents recommended that; the challenges can be solved by local community to cultivate pepper and other stakeholders such as district, different NGO and companies to support farmers the provision of used oil,chill should be applied regularly once washed out by rain and for the effectiveness of the method community should be more trained on how to use the method.

\subsection{Recommendations}

$\checkmark$ Community should cultivate more peppers to simplify the exercise of chilling method.

$\checkmark$ Government officialssuch as VEO or WEO should have to report immediately to game officers once elephants destruct crops.

$\checkmark$ Districts Authorities should have to collaborate with other companies outside the district such as Barick Company Limited to support the provision of used oil to the farmer.

$\checkmark$ Capacity building of local wildlife managers to deal with HEC

$\checkmark$ The government should have to develop substantial benefits for local communities living adjacent to the protected areas to increase local tolerance of HEC.

$\checkmark$ Frequency application of the method should be intensified particularly during rain season.

$\checkmark$ Capacity building on how to use the method particularly on the ratio required.

\section{REFERENCES}

[1] Bouma, G.D. (2000). The research Process $\left(4^{\text {th }}\right.$ ed $)$.Oxford University Press, London.

[2] Breitenmoser, U.R.S., Angst, C., Landry, J., Breitenmoser-Wursten, C., Linnell, J. \& Webber, J. (2005).Non-lethal Techniques for Reducing Depredation. In R. Woodroffe; S. Thirgood\& A. Rabinowitz (Eds.), People and wildlife: conflict or existence? (pg 49-71). Cambridge, UK: Cambridge University Press.

[3] Coffey, A.\& Atkinson, P. (1996).Making Sense of Qualitative Data: Complementary Research Strategies. Thousand Oaks, CA: Sage. 
[4] Distefano, E. (2005). Human- Wildlife Conflicts Worldwide:ACollection of Case Studies, Analysis of Management Strategies and Good Practices. SARD Initiative Report, FAO, Rome.

[5] FAO,(2005).Strategies to mitigate Human-Wildlife Conflict in Mozambique.Anderson, J. \&Pariela, F. Report for the National Directorate of Forests \& Wildlife. Pg 68 .

[6] Gillham, B. (2005). Research Interviewing: The Range of Techniques: London: Open University.

[7] Henn, M., Weinstein, M., Foard, N. (2006).A Short Introduction to Social Research.Sage Publications, London.

[8] Hesse-Biber, S., \&Leavy, P. (2004). Approaches to Qualitative Research: A Reader on Theory and Practice. Oxford University Press.

[9] Hoare, R.E. (2001a). A decision support system for managing human-elephant conflict situations in Africa.Pages 1-110.IUCN African Elephant Specialist Group Report.

[10] Hoare, R.E. (2001b). Management implications of new research on problem elephants.Pachyderm, 30: 44-49.

[11]Holmern, T \&Anne B. (2004), "Human -wildlife conflicts and hunting in the Western Serengeti Tanzania."NINA Project Report, No 26.

[12] Homewood, K., Lambin, E.F., Coast, E(2001).Long term changes in Serengeti-Mara Wildebeest and Land Cover pastoralism, population or policies? Proceedings of the National Academy of Sciences of the USA.

[13] Jackson, T.P., Mosojane, S., Ferreira, S.M. \& van Aarde, R.J. (2008). Solutions forelephant Loxodontaafricanacrop raiding in northern Botswana: moving away fromsymptomatic approaches. Oryx 42, 83-91

[14] Jones, B. T. B. \& Elliott, W. J. (2006). Human Wildlife Conflict in Namibia: Experiences from a Portfolio of Practical Solutions. Nature \&Faune21, 20-25.

[15] Kaswamila, A.L., Shaun, R., \&McGibbon, M. (2007).Impacts of Wildlife on Household Food Security and Income in Northeastern Tanzania.J. Human Wildlife Dimension, 12: 391-404.

[16] Kaswamila, A. (2009). Impacts of Game on Household Food Security: A Case of Serengeti District, University ofDodoma -Department of Geography and Environment.

[17] Kideghesho, J.R. (2006).Constraints in Implementing the Benefit-Based approaches as a Strategy for Conserving WildlifeIn Western Serengeti, Tanzania, A paper presented at the 11th Biennial Conference of the International Association for the Study of Common Property in Bali, Indonesia June 19-23, 2006.

[18] Kideghesho, J.R.Nyahongo,J. W,Hassan, S.N, Tarimo,T.C, \&Mbije, N.E. (2006),Factors and Ecological Impacts of Wildlife Habitat Destruction in Serengeti Ecosystem in Northern Tanzania.Sokoine University of Agriculture,Department of Wildlife, Morogoro,Tanzania.

[19] Krueger, A., Kahneman, D., Schkade, D., Schwarz, N. and Stone, A. (2004), Measuring the Subjective Well-Being of Nations: National Accounts of Time Use and Well-Being, National Bureau of Economic Research, University of Chicago Press, 79 pp.

[20] Morgan, D.L.(1998).Focus Groups as Qualitative Research, London; Sage.

[21] Muruthi, P. (2005). Human Wildlife conflicts: Lessons learned from AWD's African heratlands. $A W F$ Working Papers, July 2005, 12 p.

[22] Parker, G.E. \& Osborn, F.V. (2006).Investigating the potential for chilli Capsicum annuum to reduce human-wildlife conflict in Zimbabwe. Oryx 40(3):1-4.

[23]Parker G.E., Osborn, F.V., Hoare R.E. \&Niskanen, L.S. (eds.) (2007): Human-Elephant Conflict Mitigation: A Training Course for Community-Based Approaches in Africa. Participant's Manual. Elephant Pepper Development Trust, Livingstone, Zambia and IUCN/SSC AfESG, Nairobi, Kenya.

[24]Punch, K. (2000). Developing Effective Research Proposals. Sage Publications, London, 125pp

[25]Rwegoshora, H.M.M. (2006). A Guide to Social Science Research, Dar es Salaam, Tanzania MkukinaNyota Publishers.

[26] Severre, E.L.M.(2000).Conservation of wildlife outside core areas in the new millennium. Dar-resalaam printers

[27]URT. (2005).Assessment of Game Controlled Area Category as Wildlife Conservation Areas.Ministry of Natural Resources and Tourism, Wildlife Division, Dar es Salaam: Government Printer.

[28] Woodroffe, R., Thirgood, S \& Rabinowitz, A. (2005). The Future of Coexistence: Resolving HumanWildlife Conflicts in Changing World. In R. Woodroffe; S. Thirgood\& A. Rabinowitz (Eds.), People and wildlife: conflict or existence? (Pg 388405). Cambridge, UK: Cambridge University Press.

[29] Woodroffe,R., $\quad$ Thirgood,S\&Rabinowitz,A. (2005),People and Wildlife Conflict orCoexistence? Cambrige University Press. 